\title{
Evaluation of Treatment for Isolated Bilateral Miller's Class I or II Gingival Recession with Platelet Rich Fibrin Membrane- A Comparative Study
}

\author{
Madhura Antharasanahalli Shivakumar ${ }^{1 *}$, Sanjay Venu Gopal', Pushpalatha Govindaraju' ${ }^{1}$, Santhosh Ramayya ${ }^{1}$, Darshana Bennadi², \\ Roopavathi Kallahalli Mruthyuenjaya' \\ 'Department of Periodontics, Sree Siddhartha Dental College and Hospital, Tumkur, INDIA. \\ ${ }^{2}$ Department Of Public Health Dentistry, Sree Siddhartha Dental College and Hospital, Tumkur, INDIA.
}

\begin{abstract}
Background: A recent innovation in dentistry is the use of second generation platelet concentrate which is an autologous platelet rich fibrin gel (PRF) with growth factors and cicatricial properties for root coverage procedures. The aim of this study was to determine the addition of an autologous plateletrich fibrin membrane (PRF) to coronally advanced flap (CAF) (site A) would improve the clinical outcome compared to an CAF alone (Site B) for the treatment of isolated Miller's Class I or II gingival recessions. Materials and Methods: Ten subjects, presenting isolated bilateral Miller Class I or II gingival recessions of similar extent were enrolled in the study. The mean recession depth value at baseline was $3.30 \pm 0.95 \mathrm{~mm}$ for test sites and $3.30 \pm 0.95 \mathrm{~mm}$ for control sites. Each patient was treated on both sides by CAF technique; the combination treatment (with PRF membrane) was applied on the test side. Probing depth (PD), recession width, clinical attachment level (CAL), keratinized gingival width, and gingival/mucosal thickness (GTH) were measured at baseline, 1 month, 3 months and at 6 months post-surgery. Results: At 6 months, complete root coverage was obtained at $73.86 \%$ of the sites treated with the test (site A) procedure but $67.52 \%$ of root coverage at the site B. A statistically significant difference between the two sites $(A \& B)$ in relation to gingival thickness was observed at
\end{abstract}

3 and 6 months. At 6 months, the increase in GTH was statistically significant when comparing the test sites (from $1.13 \pm 0.08 \mathrm{~mm}$ at baseline to $1.58 \pm 0.12 \mathrm{~mm}$ at 6 months) to the control sites (from $1.13 \pm 0.08 \mathrm{~mm}$ at baseline to $1.31 \pm 0.07 \mathrm{~mm}$ at 6 months). In the case of Recession width, PD, CAL and Width of keratinized gingiva (WKG) there was no significant difference. Conclusion: The addition of PRF membrane with CAF provides superior root coverage with additional benefits of gain in CAL and WKG at 6 months postoperatively.

Key words: Coronally advanced flap, Clinical attachment level, Gingival thickness, Gingival recession, Platelet rich fibrin membrane.

Correspondence :

Dr Madhura Antharasanahalli Shivakumar,

Department of Periodontics, Sree Siddhartha Dental College and Hospital,

Tumkur, INDIA.

Phone no.: +91-9620161180;

E-mail:dr.madura.as@gmail.com

DOI: 10.5530/jyp.2016.3.7

\section{INTRODUCTION}

Gingival recession is the displacement of the gingival margin apical to the cemento-enamel junction (CEJ). ${ }^{1}$ It is observed more frequently on the buccal surfaces of the teeth and is probably one of the most common aesthetic concerns associated with the periodontal tissues. It has been associated with many factors such as inflammatory periodontal disease, developmental anatomic abnormalities (aberrant frenal attachment, thin bony plate), toothbrush injury, tooth malposition and iatrogenic factors. ${ }^{2}$ Apart from compromised esthetics, gingival recession also results in a variety of other problems such as root hypersensitivity, a higher incidence of root caries and diminished plaque control, thus necessitating treatment.

Over the years, numerous surgical techniques such as pedicle grafts and free autografts have been introduced to correct gingival recession defects. Combination grafts with either autografts or allografts and newer concepts of guided tissue regeneration (GTR), platelet concentrates, etc. were developed more recently to correct mucogingival defects. The goals of treatment are to restore the tissue margin to the CEJ and to create a normal gingival sulcus with functional attachment. ${ }^{3}$

The Coronally advanced flap (CAF) is a simple pedicle flap that can be used for root coverage and does not require graft harvesting. ${ }^{4}$ Recently study have showed that CAF alone produced excellent defect coverage when sites had, adequate tissue coverage. ${ }^{5}$

However, some data has shown that root coverage associated with CAF used alone is unstable in long term, where it decreases from $89 \%$ at one month postoperatively to $58.8 \%$ after 6 months. A potential limitation of the CAF is the limited gain in the apico-coronal dimension of the keratinized tissue, which is an important parameter in preventing the recurrence of gingival recession. Therefore, data indicate that the CAF used alone is less than optimal technique to achieve root coverage despite having the advantage of generating low morbidity. A surgical technique that can be combined with CAF in order to overcome its limitations is desirable for the management of gingival recession. ${ }^{4}$

Amongst the various treatment modalities, the sub-epithelial connective tissue grafting holds the most promising results. A systematic review by Chambrone et al $(2008)^{6}$ revealed that sub-epithelial connective tissue grafts (SCTG) provided significant root coverage, clinical attachment and keratinized tissue gain as compared to various other procedures and hence could be considered as the "gold standard" procedure in the treatment of gingival recession defects. However, the problems that relate to the use of autogenous tissue grafting include a limited amount of source material and increased morbidity due to the second surgical site, making the technique less than ideal in certain cases. In addition, the healing involves a long junctional epithelium, mainly with a limited amount of connective tissue attachment. ${ }^{7,8}$

Obtaining root coverage has become more predictable with advances in the understanding of soft tissue healing and maturation. Various growth factors have shown to enhance wound healing as well as facilitate regeneration of periodontal tissues. Platelet rich fibrin (PRF) is a second generation platelet concentrate, which is a concentrated suspension of growth factors like platelet-derived growth factor (PDGF), transforming growth factor- $\beta$ (TGF- $\beta$ ), insulin-like growth factor (IGF) found in platelets. PRF is known to accelerate wound healing, as well as hard and 
soft tissue maturation when used in conjunction with various root coverage procedures. ${ }^{9}$ Hence, this study was aimed to compare Coronally advanced flap (CAF) alone or in conjunction with an autologous platelet rich fibrin clot (PRF) in treatment of Miller's Class I and Class II recession defects through evaluating the amount of root coverage and gingival thickness obtained by both the procedures.

\section{MATERIALS AND METHODS}

Study selected ten study subjects from patients attending the outpatient department of Periodontics, Sri Siddhartha Dental College and Hospital, Tumkur. The patients of either sex within the age range of 18-45 years, with bilateral Miller's class I and II recession defects, without any contraindication for periodontal surgery and systemically healthy were included in the study. Patients with inflammatory periodontal disease, previous surgical attempt, with systemic disease or severe immune deficiency; coagulation defects or on anticoagulation treatment; addiction to drugs or pregnancy were excluded from the study. So our sample size was 10 patients. After the patient were selected for the study based on inclusion and exclusion criteria, treatment procedure was explained to the patient and written informed consent was taken from each patient before starting the treatment. The study protocol was approved by the Ethical committee of Institution.

Twenty sites (Bilaterally in single patient) in oral cavity from ten patients were selected for the study. A randomized controlled single-blind splitmouth clinical trial was employed and the selected sites were randomly divided with a flip of a coin into experimental site A and experimental site B.

Experimental site A: Root coverage was performed with PRF and coronal advancement of the flap (Figure 1-6).

Experimental site B: Root coverage was performed by coronal advancement of the flap alone (Figure 7-10).

Later, Plaque Index (Silness and Loe, 1964), ${ }^{10}$ Gingival Index (Loe and Silness, 1963), ${ }^{10}$ Recession depth and width, Width of keratinized gingiva (assessed with the roll test), Probing Pocket depth, Clinical attachment level, Gingival thickness. All clinical parameters were recorded preoperatively at baseline and at 1 month, 3 months and 6 months postoperatively.

The percentage of root coverage was calculated using the formula:

$$
\begin{aligned}
& \text { Recession depth (Pre-operative- } \\
& \text { Root coverage }=\frac{\text { Post-operative }) \times 100}{\text { Recession depth pre }- \text { operatively }}
\end{aligned}
$$

Occlusal Stents provided fixed angulations for measurements of parameters pre-operatively as well as post-operatively. All the customized acrylic stents were stored on the prepared study cast throughout the study period to minimize distortion. Patients with acceptable oral hygiene after Phase I therapy were enrolled for surgery.

Adequate anaesthesia with $2 \%$ lignocaine $\mathrm{HCl}$ containing 1:80,000 adrenaline was obtained at the surgical site. A no. 15 blade was used for the incision at the level of the CEJ in the mesial and distal interdental papilla adjacent to the recession area. Starting at the mesial line angle and the distal line angle of the study tooth, two vertical incisions were made extending beyond the mucogingival junction. A sulcular incision was made to connect the two vertical incisions. A full thickness flap was raised about 3-4 mm apical to the crest of the osseous dehiscence. A periosteal releasing incision was given to enable the coronal displacement of the flap.

$5 \mathrm{ml}$ of blood was drawn intravenously from the antecubital vein of each patient and centrifuged immediately. Blood was centrifuged using a table top centrifuge for $12 \mathrm{~min}$ at 2700 revolutions per minute (rpm). PRF clot was separated and used. ${ }^{11}$

The surgical procedure involved the reflection of full thickness flap up to the mucogingival junction by giving a sulcular incision with vertical releasing incisions at the mesial and distal line angles of the involved tooth.

Experimental Site A: The PRF membrane was trimmed and contoured as required to cover the recipient site. PRF was placed over the denuded root surface, extending from 2-3 mm apical to the crest of the osseous dehiscence at the CEJ. It was secured in position with 5-0 vicryl sutures. The flap was coronally positioned over the membrane and secured with 5-0 vicryl sutures. Experimental site B: A periosteal releasing incision was given to enable the coronal displacement of the flap. The flap was repositioned, with its margins located on the enamel, and held in that position with 3-0 silk suture around the contact points.

The surgical areas in both sites were covered with a non-eugenol periodontal dressing (Coe-Pak, GC America Inc, USA). Post-operative antibiotics and analgesics were prescribed. Post-operative instructions were given to all the patients.

The patients were recalled after 10 days for suture removal at experimental site B. Patients were questioned regarding symptoms of pain, discomfort and sensitivity. Any signs of swelling, infection, flap displacement, hematoma were noted. They were recalled at 1 month, 3 months and 6 months intervals for evaluation of clinical parameters. At each visit, oral hygiene instructions were reinforced and deplaquing was done, if required.

The data was analyzed using statistical software MedCalc 10.2. Mean \pm Standard deviation was calculated for all clinical parameters at baseline, 1 month, 3 months and 6 months. The Wilcoxon's signed-rank test was used to analyze the differences in the clinical parameters (Recession depth, Recession width, Probing pocket depth, Clinical attachment level and Width of keratinized gingiva and gingival thickness) in both groups at different examinations (at baseline, 1 month, 3 months and 6 months). The analysis for the effect of each treatment from baseline to each postoperative visit (at 1 month, 3 months and 6 months) for all parameters were done using Mann-Whitney $\mathrm{U}$ test. The level of significance was 0.05 .

\section{RESULTS}

The study was carried out in 10 patients (eight males and two females) with a mean age of $28.41 \pm 7.15$ years. Clinical healing progressed uneventfully in both the treatment sites and no adverse complications were noticed or reported.

The results of the clinical parameters recorded are as follows: The mean plaque index and gingival index scores decreased and the difference was statistically significant at all post-operative visits as compared to the baseline value (Table 1) ( $>0.05)$.

Mean pre-operative measurements at Experimental site $\mathrm{A}$ and site B: The patients presented with contra lateral recession defects with similar preoperative clinical parameters (Recession depth, Recession width, Probing pocket depth, Clinical attachment level and Width of keratinized gingiva). There was no statistically significant difference between the recession defects in the two groups at baseline as shown by Mann-Whitney U test $(\mathrm{p}>0.05)$ (Table 2).

Mean post-operative measurements at Experimental site A and site B: Both the groups showed significant improvement in clinical parameters (Recession depth, Recession width, Probing pocket depth, Clinical attachment level and Width of keratinized gingiva) at the end of 6 months. The inter-group analysis showed that the difference in the reduction in the probing pocket depth was not statistically significant ( $p>0.05$ ) (Table 3-7) except gingival thickness (Table 8 ) which was statistically significant $(\mathrm{p}<0.01)$ in both groups. 
Table 1: Mean reduction in plaque index and gingival index by Wilcoxon matched pairs test (mean \pm SD in $\mathrm{mm}$ )

\begin{tabular}{lccc}
\hline & Plaque index score & Gingival index score & P value \\
\hline Baseline & $0.48 \pm 0.09$ & $0.53 \pm 0.16$ & - \\
1 month & $0.42 \pm 0.08$ & $0.51 \pm 0.14$ & $\mathrm{P}=0.0051^{*}$ \\
3 month & $0.35 \pm 0.07$ & $0.49 \pm 0.11$ & $\mathrm{P}=0.0051^{*}$ \\
6 month & $0.32 \pm 0.04$ & $0.42 \pm 0.12$ & $\mathrm{P}=0.0051^{*}$ \\
\hline
\end{tabular}

${ }^{*} \mathrm{p}<0.05$, \# applied Wilcoxon matched pairs test.

Table 2: Comparison of mean pre-operative measurements at Experimental site $A$ and $B$ by Mann-Whitney $U$ test (mean $\pm S D$ in $\mathrm{mm}$ )

\begin{tabular}{cccc} 
& $\begin{array}{c}\text { Experimental } \\
\text { site A }\end{array}$ & $\begin{array}{c}\text { Experimental } \\
\text { site B }\end{array}$ & p value \\
\hline Recession depth & $3.30 \pm 0.95$ & $3.30 \pm 0.95$ & $1.000^{+}$ \\
Recession width & $2.70 \pm 0.82$ & $2.70 \pm 0.82$ & $1.000^{+}$ \\
Probing depth & $2.60 \pm 0.52$ & $2.60 \pm 0.52$ & $1.000^{+}$ \\
Clinical attachment level & $5.90 \pm 1.29$ & $5.90 \pm 1.29$ & $1.000^{+}$ \\
Width of keratinized gingiva & $1.90 \pm 0.57$ & $1.90 \pm 0.57$ & $1.000^{+}$ \\
Gingival thickness & $1.13 \pm 0.08$ & $1.13 \pm 0.08$ & $1.000^{+}$ \\
\hline
\end{tabular}

+ Not significant.

Table 3: Comparison of recession depth at Experimental site $A$ and $B$ (mean $\pm S D$ in $\mathrm{mm}$ )

\begin{tabular}{cccc}
\hline & Experimental site A & Experimental site B & P value \\
\hline Base line & $3.30 \pm 0.95$ & $3.30 \pm 0.95$ & 1.0000 \\
1 month & $1.80 \pm 0.92$ & $1.80 \pm 0.92$ & 1.0000 \\
3 month & $0.90 \pm 0.74$ & $1.00 \pm 0.67$ & 0.7624 \\
6 month & $0.80 \pm 0.79$ & $1.00 \pm 0.67$ & 0.5454 \\
p value (baseline to each & $\mathrm{P}=0.0051^{*}$ & $\mathrm{P}=0.0051^{*}$ & \\
post-op month) & & & \\
Difference between & & & \\
baseline and & & & \\
6 months & $2.50 \pm 0.16$ & & \\
\hline
\end{tabular}

${ }^{*} \mathrm{p}<0.05$, \# applied Wilcoxon matched pairs test.

Table 4: Comparison of recession width at Experimental site $A$ and Experimental site $B$ (mean \pm SD in)

\begin{tabular}{cccc}
\hline & Experimental site A & Experimental site B & P value \\
\hline Base line & $2.70 \pm 0.82$ & $2.70 \pm 0.82$ & 1.0000 \\
1 month & $1.30 \pm 0.67$ & $1.30 \pm 0.67$ & 1.0000 \\
3 month & $0.90 \pm 0.74$ & $1.00 \pm 0.67$ & 0.7624 \\
6 month & $0.70 \pm 0.67$ & $0.90 \pm 0.57$ & 0.4963 \\
$\begin{array}{c}\text { p value* (baseline to each } \\
\text { post-op month) } \\
\begin{array}{c}\text { Difference between } \\
\text { baseline and } \\
6 \text { months }\end{array}\end{array}$ & $\mathrm{P}=0.0051^{*}$ & $\mathrm{P}=0.0051^{*}$ & \\
\hline
\end{tabular}

Wilcoxon signed-rank test+Not significant Mann-Whitney U test ++ Very significant. 
Table 5: Comparison of probing pocket depth at Experimental site $A$ and Experimental site $B$ (mean \pm SD in $\mathbf{~ m m}$ )

\begin{tabular}{cccc}
\hline & Experimental site A & Experimental site B & P value \\
\hline Base line & $2.60 \pm 0.52$ & $2.70 \pm 0.52$ & 1.0000 \\
1 month & $1.60 \pm 0.52$ & $1.60 \pm 0.52$ & 1.0000 \\
3 month & $1.00 \pm 0.00$ & $1.00 \pm 0.00$ & 1.0000 \\
6 month & $0.90 \pm 0.32$ & $1.00 \pm 0.00$ & 0.7055 \\
p value* (baseline to each & $\mathrm{P}=0.0051^{*}$ & $\mathrm{P}=0.0051^{*}$ & \\
post-op month) & & \\
$\begin{array}{c}\text { Difference between } \\
\text { baseline and }\end{array}$ & $1.70 \pm 0.20$ & $1.70 \pm 0.52$ & 0.7055 \\
6 months & & & \\
\hline
\end{tabular}

${ }^{\star} \mathrm{p}<0.05$, \# applied Wilcoxon matched pairs test.

Table 6: Comparison of clinical attachment level at Experimental site $A$ and site $B$ (mean \pm SD in $\mathrm{mm}$ )

\begin{tabular}{cccc}
\hline & Experimental site A & Experimental site B & P value \\
\hline Base line & $5.90 \pm 1.29$ & $5.90 \pm 1.29$ & 1.0000 \\
1 month & $3.20 \pm 1.23$ & $3.20 \pm 1.23$ & 1.0000 \\
3 month & $2.00 \pm 0.67$ & $2.00 \pm 0.67$ & 1.0000 \\
6 month & $1.60 \pm 1.07$ & $1.80 \pm 1.03$ & 0.6502 \\
p value (baseline to each & $72.88 \% \#$ & $69.49 \% \#$ & \\
post-op month) & $\mathrm{P}=0.0051^{*}$ & $\mathrm{P}=0.0051^{*}$ & \\
Difference between & & & 0.5205 \\
baseline and & $4.30 \pm 0.20$ & $4.10 \pm 0.52$ & \\
6 months & & & \\
\hline
\end{tabular}

${ }^{*} \mathrm{p}<0.05$, \# applied Wilcoxon matched pairs test.

Table 7: Comparison of width of keratinized gingiva at Experimental site $A$ and site $B$ (mean $\pm S D$ in $\mathbf{m m}$ )

\begin{tabular}{cccc}
\hline & Experimental site A & Experimental site B & P value \\
\hline Base line & $1.90 \pm 0.57$ & $1.90 \pm 0.57$ & 1.0000 \\
1 month & $2.80 \pm 0.42$ & $2.80 \pm 0.42$ & 1.0000 \\
3 month & $3.50 \pm 0.53$ & $3.50 \pm 0.53$ & 1.0000 \\
6 month & $3.70 \pm 0.82$ & $3.70 \pm 0.82$ & 1.0000 \\
p value (baseline to each & $-94.74 \% \#$, & $-94.74 \% \#$, & \\
post-op month) & $\mathrm{P}=0.0051^{*}$ & $\mathrm{P}=0.0051^{*}$ & \\
Difference between & & & 1.0000 \\
baseline and & $-1.80 \pm 0.15$ & $-1.80 \pm 0.15$ & \\
6 months & & & \\
\hline
\end{tabular}

${ }^{*} \mathrm{p}<0.05$, \# applied Wilcoxon matched pairs test.

Table 8: Comparison of Gingival thickness at Experimental site $A$ and site $B$ (mean \pm SD in mm)

\begin{tabular}{cccc}
\hline & Experimental site A & Experimental site B & P value \\
\hline Base line & $1.13 \pm 0.08$ & $1.13 \pm 0.08$ & 1.0000 \\
1 month & $1.39 \pm 0.09$ & $1.24 \pm 0.08$ & $0.0036^{*}$ \\
3 month & $1.51 \pm 0.13$ & $1.28 \pm 0.10$ & $0.0013^{*}$ \\
6 month & $1.58 \pm 0.12$ & $1.31 \pm 0.07$ & $0.0004^{*}$ \\
p value* (baseline to each & $-39.82 \% \#, \mathrm{P}=0.0051^{*}$ & $-15.93 \% \#, \mathrm{P}=0.0060^{*}$ & \\
post-op month) & & & \\
Difference between & & $-0.17 \pm 0.05$ & $0.0002^{*}$ \\
baseline and & $-0.45 \pm 0.04$ & & \\
6 months & & &
\end{tabular}

${ }^{*} \mathrm{p}<0.05$, \# applied Wilcoxon matched pairs test. 


\section{Surgical Procedure-Experimental Site A [Coronally Advanced Flap In Combination With A Platelet Rich Fibrin} Membrane]

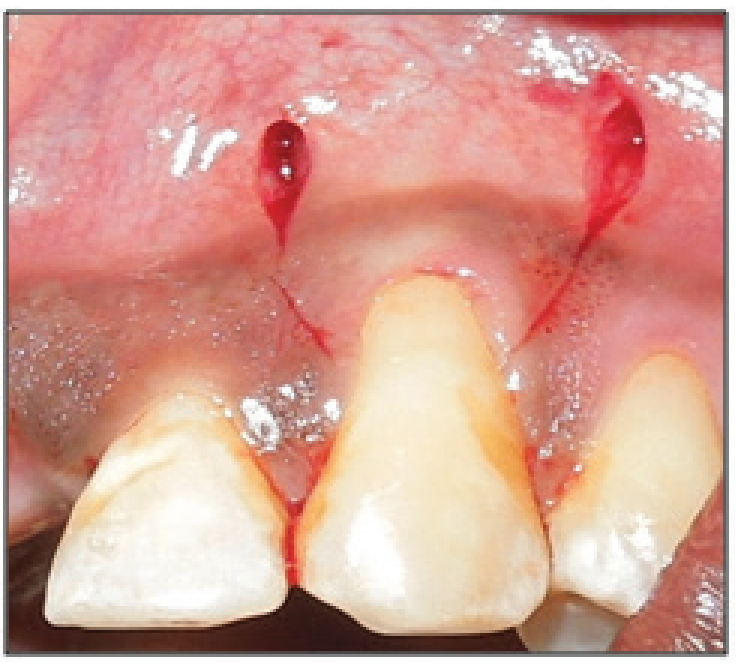

Figure 1: Incision.

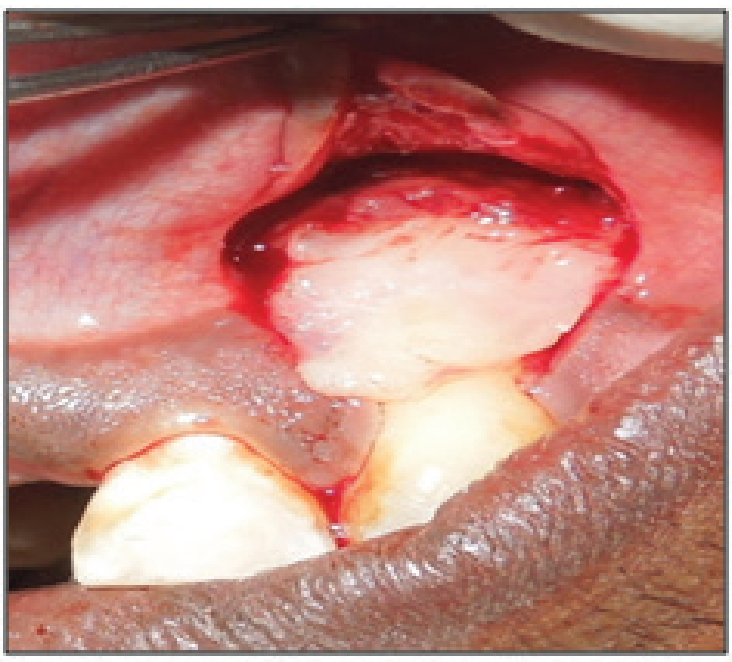

Figure 3: PRF placed on denuded root surface.

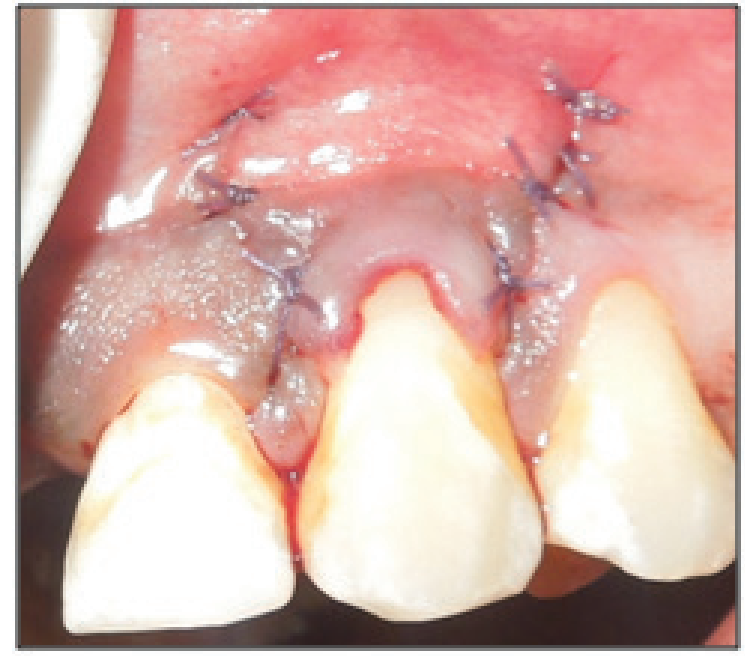

Figure 5: Flap is coronally advanced and sutured.

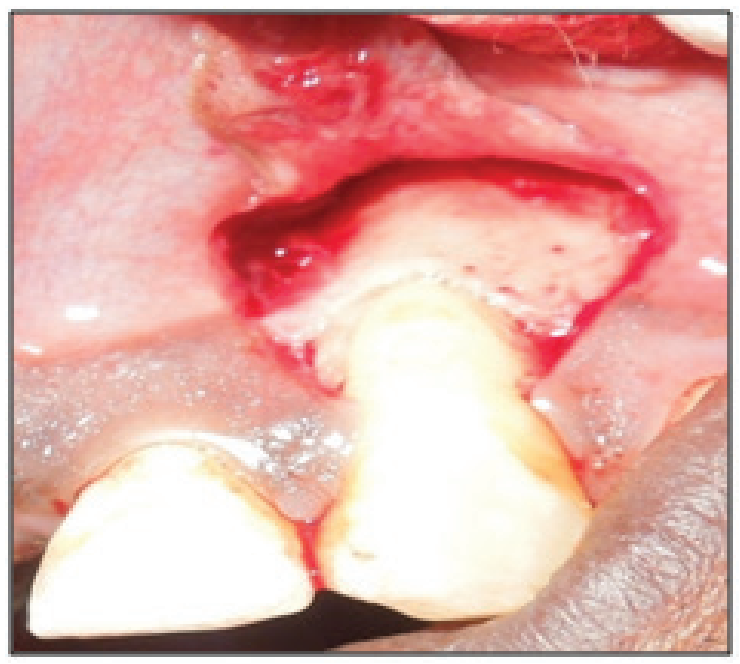

Figure 2: Flap reflection.

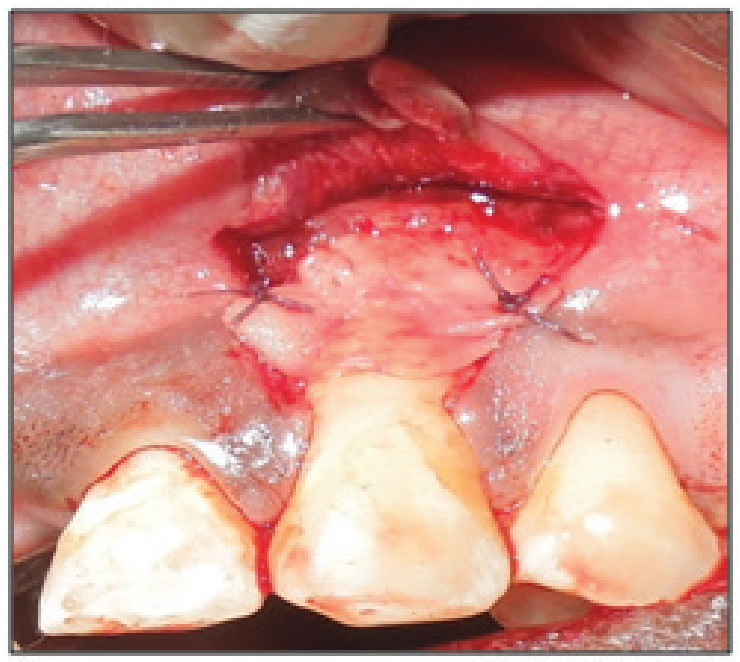

Figure 4: Suturing of PRF membrane

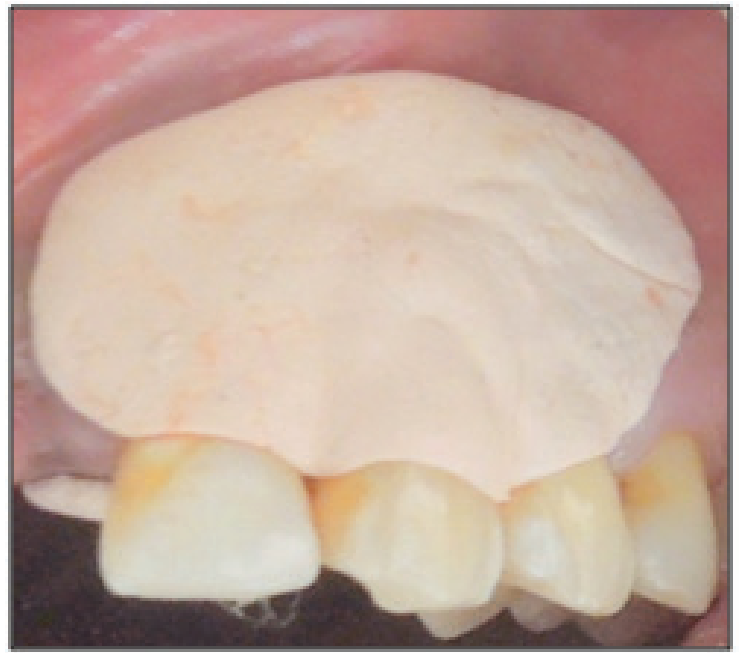

Figure 6: Periodontal pack placed. 


\section{Surgical Procedure-Experimental Site B [Coronally Advanced Flap Alone]}

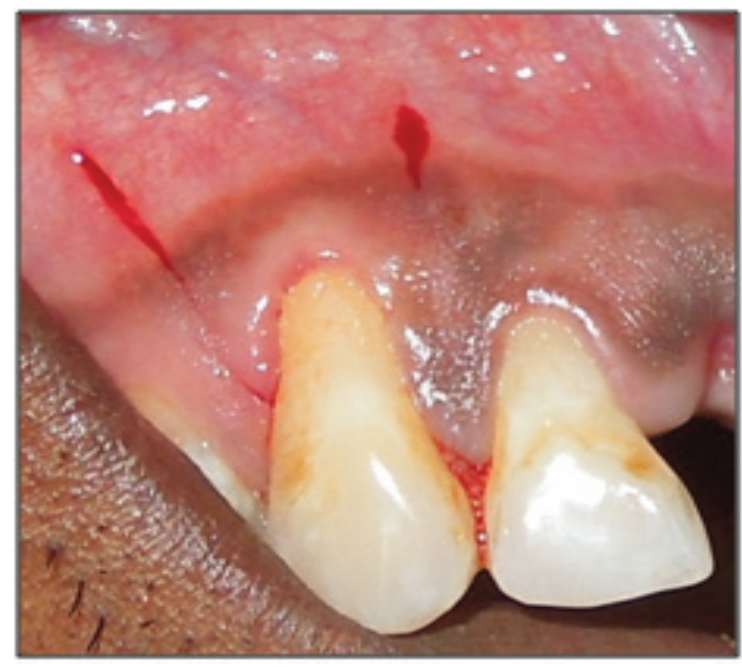

Image 07: Incision.

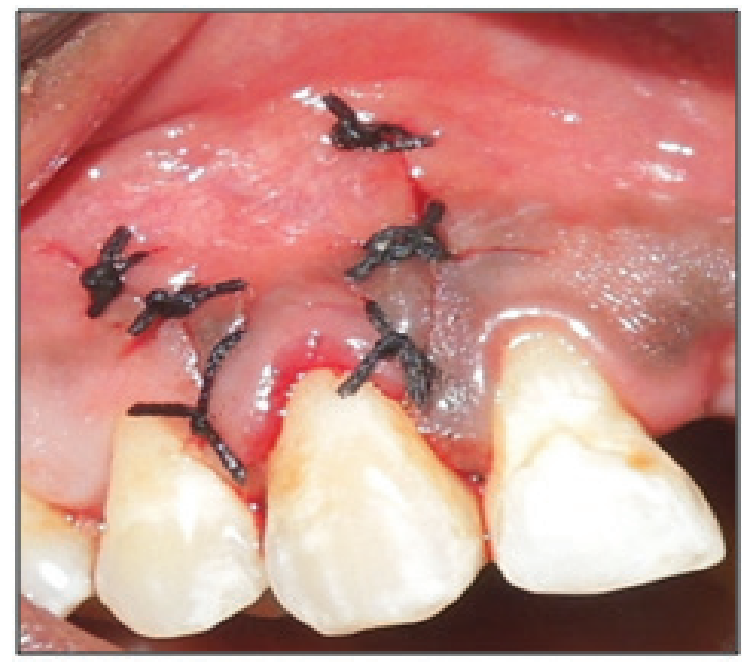

Image 09: Coronal advancement of flap.

\section{DISCUSSION}

Periodontal therapy has been directed primarily at elimination of periodontal disease and maintaining the function and health of the dentition and the supporting tissues. More recently, periodontal therapy has become increasingly focused on esthetic outcomes, which extend beyond tooth replacement and tooth colour to include the surrounding soft tissues. Gingival recession is one of the most common esthetic and functional concerns associated with the periodontal tissues. ${ }^{12,13}$ Investigation of etiologic factors and consideration of therapeutic options directed at complete root coverage aid in achieving an esthetic and natural appearance of the newly gained tissue. To accomplish these objectives, many surgical techniques have been described. Pedicle grafts, free gingival grafts, connective tissue grafts combined with pedicle grafts, acellular dermal matrix grafts and guided tissue regeneration have shown to produce effective outcomes. ${ }^{14}$

Among the various techniques employed to correct gingival exposure, the coronally advanced flap (CAF), alone or combined with other proce-

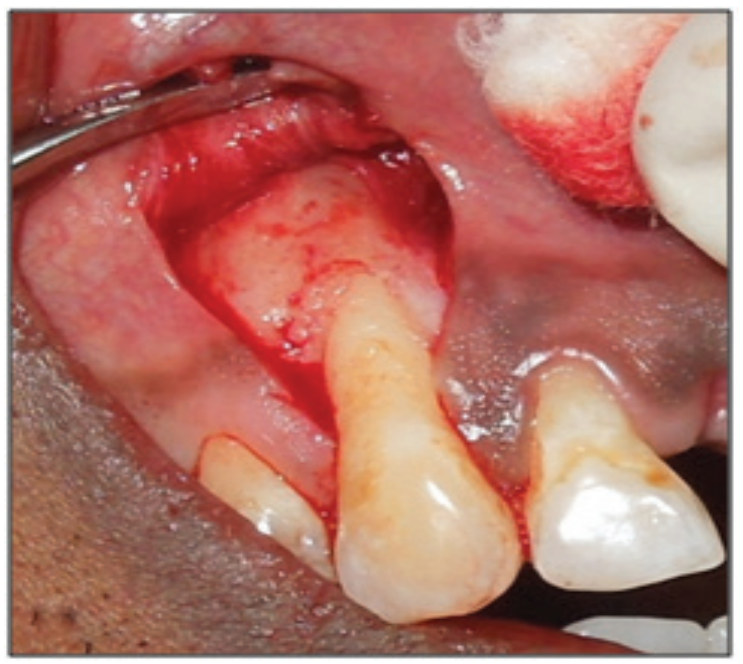

Image 08: Flap reflection.

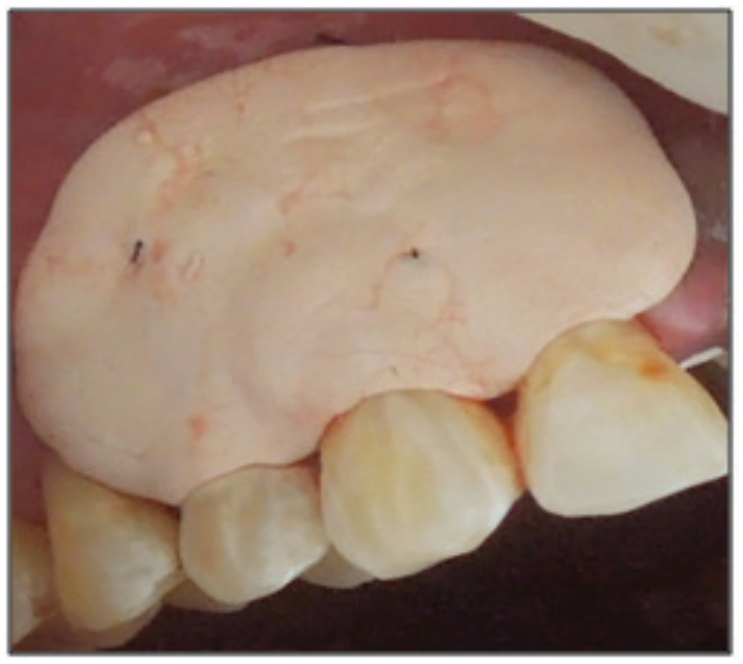

Image 10: Periodontal dressing placed.

dures, e.g. subepithelial connective tissue graft (SCTG), has been one of the most widely used procedures in the treatment of Miller's Class I or II gingival recessions. ${ }^{15}$ To improve the predictability of clinical outcomes of various periodontal surgeries as well as to enhance the soft and hard tissue healing, the use of Platelet rich fibrin has recently evolved. ${ }^{9,16} \mathrm{PRF}$ is a platelet concentrate releasing various growth factors critical in the regulation and stimulation of the wound healing process. Platelet concentrates have also shown superior esthetic outcomes when compared with SCTG. ${ }^{17}$ Thus, based on the above facts, the aim of the present study was to compare the clinical outcomes of Coronally advanced flap alone or in combination with platelet rich fibrin in the treatment of Miller's Class I and Class II gingival recession defects.

In the present study, the full mouth Plaque and Gingival index scores remained low throughout the study period. It was observed that there was a significant reduction in the gingival index as well as the Plaque index scores postoperatively (Table 1 , Table 2 ). This reduction in scores could be attributed to the regular oral hygiene instructions given to the 
patients thereby enabling improved plaque control efficiency and better patient compliance, generally observed following periodontal surgery. ${ }^{18}$ It could also imply that both the treatments were well tolerated by the host tissues and it did not enhance plaque accumulation or gingival inflammation.

It was observed that both $\mathrm{CAF}+\mathrm{PRF}$ and $\mathrm{CAF}$ techniques were capable of decreasing the amount of root exposure and obtained adequate root coverage. The results of the present study are in agreement with studies carried out by Rajan padma et al. ${ }^{19}$ In which there was a mean root coverage of $100 \%$ in the CAF+PRF group and $68 \%$ in the CAF group in fifteen patients treated for Miller's Class I or II gingival recession defects.

In our study, although, no statistically significant differences in the treatment outcomes were found between the two groups, the results tend to favour the CAF+PRF group. 4 out of 10 sites in the CAF+PRF group obtained $100 \%$ root coverage, while only 2 out of 10 sites in the CAF group obtained $100 \%$ root coverage. This difference could be explained by the influence of tissue thickness on the predictability of root coverage procedures.

Both the procedures demonstrated a statistically significant improvement in the recession width, post-operatively. But the difference between the two groups was statistically non significant. Our results were in accordance to studies carried out by Eren G, Atilla G. ${ }^{20}$

Reduction in probing pocket depth was observed with both the surgical techniques. CAF+PRF group resulted in greater reduction $(1.70 \pm 0.20 \mathrm{~mm})$ than CAF group $(1.70 \pm 0.52 \mathrm{~mm})$. The results of the present study were comparable to studies by Aroca $S$ et al 2009. ${ }^{21}$

CAL gain was evident post-therapy with both the procedures. A gain of $4.30 \pm 0.20 \mathrm{~mm}$ was seen with the CAF+PRF group and $4.10 \pm 0.52 \mathrm{~mm}$ with CAF group at 6 months. The significant decrease in the recession depth and the probing pocket depth could have contributed to the gain in CAL. These results were similar to studies by Rajan padma et al. ${ }^{19}$

It has been stated that an increase in the amount of keratinized tissue is a desired effect in decreasing the possibility of recurrence of gingival recession..$^{22}$ In the present study, both the techniques showed statistically significant gain in the width of keratinized tissue. The findings of the present study were similar to studies carried out by Eren G, Atilla G, ${ }^{20}$ and Rajan padma et al. ${ }^{19}$

The present study results revealed a statistically significant gain in the thickness of gingiva in both the experimental groups. The mean gain of gingival thickness in CAF+PRF group was $(1.58 \pm 0.12 \mathrm{~mm})$ and $(1.31 \pm$ $0.07 \mathrm{~mm}$ ) with CAF group at 6 months. The findings of the present study were similar to studies carried out by Aroca S, ${ }^{21}$ And Gulnihal Eren and Gul Atilla. ${ }^{23}$

In the present study, an improvement in the root coverage was observed with time. This improvement could be attributed to a possible "creeping attachment" and tissue maturation taking place post-operatively. ${ }^{24,25}$ Borghetti and Gardela (1990) suggested any increases in attachment after 1 month of healing should be considered as creeping attachment and that though the amount of creeping attachment is generally minimal, it is clinically important as it increases the predictability of the procedure. ${ }^{24,26}$ Results from the present study indicated that CAF+PRF and CAF could be successfully used to treat Miller's Class I and Class II gingival recession defects. Both the groups demonstrated an overall significant improvement in all the assessed clinical parameters. Although, the result of this study found no significant difference between the two groups with regards to outcome of the treatment, a trend towards greater improvement was seen in the $\mathrm{CAF}+\mathrm{PRF}$ group. This finding was similar to that reported by Gulnihal Eren and Gul Atilla ${ }^{23}$ and Rajan padma et al. ${ }^{19}$

According to Wilderman and Wentz (1965), the healing of a pedicle flap on a denuded root surface includes the following four stages-adaptation, proliferation, attachment and finally maturation. ${ }^{27}$ In the early stages of healing, a thin fibrin layer appears between the root surface and the flap, which eventually gets invaded by the connective tissue cells proliferating from the subsurface of the flap. The cells proliferating from the periodontal ligament space are then differentiated into cementoblasts, osteoblasts and fibroblasts. Similarly, the exposure of root surface to PRF provides a scaffold for cell migration, proliferation and upregulation of collagen synthesis in the extracellular matrix. Platelet degranulation releases various growth factors which promote regeneration, rapid angiogenesis and easier remodeling of fibrin in a more resistant connective tissue, thereby enhancing wound healing. ${ }^{17}$ PRF has also shown to improve the final esthetic result of periodontal soft tissues along with hard and soft tissue maturation when used in conjunction with various root coverage procedures. ${ }^{9}$ These beneficial properties of PRF could have played a contributing role in helping us achieve results comparable to SCTG.

\section{CONCLUSON}

CAF+PRF and CAF can be used to successfully treat Miller's Class I and Class II gingival recession defects. Similar results obtained by both the treatment modalities indicate that $\mathrm{CAF}+\mathrm{PRF}$ could be used as an alternative technique to SCTG, thereby aiding in overcoming the relevant limitations of an autogenous grafting technique. However, it is imperative that further long-term clinical and histological studies are performed to validate the effectiveness of this technique.

\section{ACKNOWLEDGEMENT}

All my study participants.

\section{CONFLICT OF INTEREST}

The author declare no conflict of interest.

\section{ABBREVIATIONS USED}

PRF: Platelet-Rich Fibrin membrane; CAF: Coronally advanced flap; CAL: Clinical Attachment Level; GTH: Gingival Thickness, PD: Probing Depth, WKG: Width of Keratinized Gingiva, SCTG: Subepithelial Connective Tissue Graft.

\section{ABOUT AUTHORS}

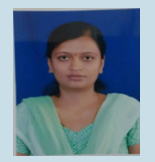

Dr. Madura AS: Periodontist, Bangalore.

Area of Interest: Bone graft, Stem cell, Regeneration. 


\section{REFERENCES}

1. The American Academy of Periodontology. Glossary of periodontal terms, $4^{\text {th }}$ edition. Chicago: The American Academy of Periodontology 2001.

2. Grant DA, Stern IB, Listgarten MA. Periodontics. $6^{\text {th }}$ edition.ST. Louis, Mosby 1988.

3. Miller PD. Regeneration and reconstructive periodontal plastic surgery: Mucogingival surgery. Dent Clin North Am. 1988;32(2):287-306.

4. Jankovic S, Aleksic Z, Iva M, Bozidar D. The Coronally Advanced Flap in Combination with Platelet-rich Fibrin (PRF) and Enamel Matrix Derivative in the Treatment of Gingival Recession: A Comparative Study. Eur J Esthet Dent. 2010;5(3):260-73.

5. Woodyard JG, Greenwell H, Hill M, Drisko C, lasell JM, Scheetz J. The clinical effect of acellular dermal matrix on gingival thickness and root coverage compared to coronally positioned flap alone. J Periodontol. 2004;75(1):44-56.

6. Chambrone L, Chambrone D, Pustiglioni FE, Chambrone LA Lima LA Can subepithelial connective tissue grafts be considered the gold standard procedure in the treatment of Miller Class I and II recession type defects? J Dent. 2008:36(9):659-71.

7. Oates T, Robinson M, Gunsolley JC. Surgical therapies for the treatment of gingival recession-A Systematic Review. Ann Periodontol. 2003;8(1):303-20.

8. McGuire MK, Cochran DL. Evaluation of human recession defects treated with coronally advanced flaps and either enamel matrix derivative or connective tissue. Part 2: Histological evaluation. J Periodontol. 2003;74(8):1126-35.

9. Anilkumar K, Geetha A, Umasudhakar, Ramakrishnan T, Vijayalakshmi R, Pameela E. Platelet rich fibrin: A novel root coverage approach. J Indian Soc Periodontol. 2009;13(1):50-4.

10. Peter S. Essentials of Preventive and Community Dentistry. $2^{\text {nd }}$ edition. New Delhi, Arya (MEDI) Publishing House. February 2004

11. Naik B, Karunakar P, Jayadev M, Marshal VR. Role of Platelet rich fibrin in wound healing: A critical review. J Conserv Dent. 2013;16(4):284-93.

12. Kassab MM, Cohen RE. The etiology and prevalence of gingival recession. J Am Dent Assoc. 2003;134(2):220-25

13. Wennstrom JL. Mucogingival therapy. Ann Periodontol. 1996;1(1):671-701.

14. Cardaropoli D, Cardaropoli G. Healing of gingival recessions using a collagen membrane with demineralized xenograft: A ranodomized controlled clinical trial. Int J Periodont Rest Dent. 2009;29(1):59-68
15. Jadson AL, Vanessa RS, Magda F, Luciene CdF, Poliana MD. Changes in the subgingival biofilm composition after coronally positioned flap. J Appl Oral Sci. 2011;19(1):68-73.

16. Sunitha RV, Munirathnam NE. Platelet rich fibrin-evaluation of second generation platelet concentrate. Indian J Dent Res. 2008;19(1):42-6.

17. Cheung WS, Griffin TJ. A comparative study of root coverage with connective tissue and platelet concentrate grafts: 8-month Results. J Periodontol. 2004;75(12):1678-87.

18. Eberhard J, Jervøe-Storm PM, Needleman I. Full-mouth treatment concepts for chronic periodontitis: a systematic review. J Clin Periodontol. 2008;35(7):591-604.

19. Rajan P, Ande S, Pavaluri AK, Meganderao N, Chetan K, Annaji S. A split mouth randomized controlled study to evaluate the adjunctive effect of platelet-rich fibrin to coronally advanced flap in Miller's class-I and II recession defects. J Indian Soc Periodontol. 2013;17(5):631-36.

20. Eren G, Atilla G. Platelet-rich fibrin in the treatment of localized gingival reces sions: a split-mouth randomized clinical trial. Clin Oral Investig. 2014;18(8):1941-8.

21. Aroca S, Keglevich T, Barbieri B, Gera I, Etienne D. Clinical evaluation of a Modified Coronally Advanced Flap Alone or in Combination with a Platelet Rich Fibrin Membrane for the Treatment of Adjacent Multiple Gingival Recessions: A 6 Month Study. J Periodontol. 2009;80(2):244-52.

22. Rosetti E, Marcantonio RA, Rossa C Jr, Chaves ES, Goissis G, Marcantonio E Jr. Treatment of gingival recession: comparative study between Subepithelial connective tissue graft and guided tissue regeneration. J Periodontol. 2000 71(9):1441-47.

23. Gulnihal E, Gul A. Platelet-Rich fibrin in the treatment of bilateral gingival recessions. J Peridontol. 2012;2(3):154-160.

24. Goldman H, Schluger S, Fox L, Cohen DW. Periodontal therapy, $3^{\text {rd }}$ ed. St Louis: CV Mosby Co.

25. Lindhe J, Lang NP, Karring T. Clinical Periodontology and Implant Dentistry. $5^{\text {th }}$ edition. Blackwell Munksgaard

26. Borghetti A, Gardela JP. Thick gingival autograft for the coverage of gingival recession. A clinical evaluation. Int $J$ Periodontics Restorative Dent. 1990;10(3):216-29.

27. Wilderman MN, Wentz FM. Repair of a dentogingival defect with a pedicle flap. J Periodontol. 1965;36(3):218-31. 